\title{
Kanser Hasta Yakınında Normal Yas Süreci, Çözümlenmeyen Yas ve Etkili Yaklaşımlar ile Onkologların Tükenmişlik Yönetimindeki Baş Etme Yöntemleri
}

\author{
Esra SAVAŞ ${ }^{1}$
}

\begin{abstract}
Özet: Yas, kişinin yaşamında yer olan herhangi bir şeyin kaybıyla ortaya çıkabilen doğal bir süreçtir. Yas süreci, sevilen eşyanın kayboluşu gibi bir nesnel geçişle de sağlık tehdidiyle de başlayabiliyor. Kanser hastalığının teşhisini kişi duyduğu an itibariyle, hastanın yaşamındaki birçok fiziksel ve duygusal değişikliğe yol açarak yas sürecini tetikleyebiliyor. Hatta bu süreç benzer şekilde hasta yakınlarında da gelişebiliyor. Yas süreci birçok durumla "normal yas" sürecinden çıkıp "çözümlenmeyen yas" sürecine dönüşebiliyor. Yas sürecindeki yaşanan duyguların ve zorlanmaların, sağlıkla yönetilebilmesi için yas sürecini tanımak ve etkili psikolojik yaklaşımlardan yararlanıyor olmak önemlidir. Tedavi ekibinin en önemli üyelerinden birisi onkologlardır. Hastalara verimli olabilmek ve hasta yakınlarıyla iyi iletişim kurabilmek için, onkologların olası tükenmişlik sendromunun farkında olması ve iyi baş etmesi önemlidir. Bu derlemedeki amaç, kanser hasta yakınlarına yönelik, hastanın vefatıyla yaşayabilecekleri normal ve çözümlenmeyen yas süreçleri açıklayıp etkili yaklaşımlarla ilgili bilgilendirmektir. Derlemenin onkologlara yönelik olan bilgilerindeki amaç; mesleki performanslarını etkileyebilecek olan tükenmişlik sendromuyla ilgili farkındalık oluşturmak ve olası durumda bahsedilen etkili tekniklerden yararlanabilmelerini sağlamaktır.
\end{abstract}

Anahtar Kelimeler: Kanser, Kanser Hasta Yakını, Normal Yas, Çözümlenmeyen Yas, Kognitif Terapi, Yas İyileştirme Programı, İfade Edici Destekleyici Yaklaşım, Çözümlenmeyen Yas Terapisi

\section{Normal Grief and Unresolved Grief in Cancer Patient's Relatives and Effective Approaches and Oncologists' Coping Ways of Burnout}

\begin{abstract}
Grief is a natural emotional process that arise after any kind of loss. This process can arise with an objective transition, such as the disappearance of a beloved item or a health threat. Cancer disease can trigger the grief process with many physical and emotional changes in the life of the person as soon as he hears it. This process can even develop similarly to the patient. The grief process can turn out of the "normal grief" process and turn into an "unresolved grief" process in so many situations. It is important to recognize the grieving process and to benefit from effective psychological approaches in order to manage the feelings and difficulties experienced in the grief process with health. One of the most important members of the treatment team is oncologists. It is important for oncologists to be aware of the possible burnout syndrome and to cope well in order to be productive and communicate well with patients' relatives. The aim of this review is to explain the normal and unresolved mourning processes that cancer patients' relatives can experience with the death of the patient and to inform them about effective approaches. The purpose of the review's information on oncologists is to raise awareness about burnout syndrome, which may affect their professional performance, and to enable them to benefit from the effective techniques mentioned in the possible situation.
\end{abstract}

Keywords: Cancer, Cancer Patient Relatives, Normal Grief, Unresolved Grief, Cognitive Therapy, Grief Recovery Program, Expressive Supportive Approach, Unresolved Grief Therapy

${ }^{1}$ Uzm. Psk., Esra Savaş Eğitim ve Danışmanlık Merkezi, Florya-İstanbul, Orcid Id: https://orcid.org/ 0000-0002-8178-6804

Address of correspondence/Yazışma adresi: Klinik Psikolog Dr \&amp; Psikoonkolog, Esra Savaş Eğitim ve Danışmanlık Merkezi. E-mail:pskesrasavas@gmail.com

Date of Received/Geliş Tarihi: 14.02.2020, Date of Revision/Düzeltme Tarihi: 15.03.2020, Date of Acceptance/Kabul Tarihi: 23.07.2020

Citing/ Referans Gösterimi: Savaş, E. (2020). Kanser Hasta Yakınında Normal Yas Süreci, Çözümlenmeyen Yas ve Etkili Yaklaşımlar ile Onkologların Tükenmişlik Yönetimindeki Baş Etme Yöntemleri. Kıbrıs Türk Psikiyatri ve Psikoloji Dergisi, 2(2): 120-5 doi:10.35365/ctjpp.20.02.17 


\section{Giris}

Kanser tedavi sürecindeki kişilerin psikolojik, sosyolojik ve fiziksel ihtiyaçları değerlendirilirken yakınlarının da en az onlar kadar destek ihtiyacı olduğu görülüyor (Given ve Given, 1998; Turner ve Catania, 1997). Kanser gibi kronik hastalığa sahip kişilere, bakım vermek veya yakını olmak; fiziksel hastalık, uyku problemi, depresyon, kişilerarası ilişkiler, sosyal ve iş yaşamında bozulma ve finansal zorlanma gibi sağllk ve iyilik halinde olumsuz etkilere yol açabiliyor (Flaskerud, 2000). Özellikle yakının, en sevdiğinin ya da hayallerinin, umutlarının çok olduğu kişinin ölüm sürecine tanık olmak, bu olumsuz etkilerin şiddetini ve gelişim riskini arttırabiliyor. Hasta yakını olarak, hastanın terminal süreçteki bedensel ve ruhsal tükenmişliği görülüyor, yok oluşu bu kadar yakından seyrediliyor ve hiçbir şey yapılamıyor. Kimi zamanda hasta yakını, elinden gelenin en iyisini yapıyor veya çabalıyor ancak hastanın tedaviye, sürece, hastalığa veya ailesine karşı direnişiyle karşılaşabiliyor. $\mathrm{Bu}$ derlemeyle paylaşılmak istenen ana konular bu zorlanmaları içermektedir. Normal ve çözümlenmeyen yasın tanımı, tepkileri, semptomları, arttıran ve azaltan etkenleri, kanser hasta yakınında yasın normal yastan fark1, klinik depresyonun ne olduğu ve bu süreçte normal yastan ayrıştırılabilmesi, yasla çalışırken en etkili psikolojik yaklaşımlar, onkologların yaşayabileceği stres ve tükenmişlik ile kendine bakım yolları yer alıyor.

\section{Normal Yas}

Yas, soyut bir kavram olduğu için öncelikle onu tanımlamak gerekir. Tirnak içinde normal olarak adlandırılan yas, değer verdiğimiz herhangi bir şeyin kaybolmasına/yok olmasına verilen doğal tepkidir. Kayıp sonrasındaki yeni yaşama uyum için olan süreçtir. Kayıp sonrası yas yaşıyor olmak, bozulmuş ruh sağlı̆̆1 gibi yanlış yorumlanıyor olsa da aslında insani duyguları içerir ve insan olduğumuzu hatırlatır. Yas yaşıyor olmak, patolojiden çok kayba yönelik verilen doğal ve normal olan tepkidir. Ayrılma ya da alışılmışın dışındaki bir durumda olumlu ve olumsuz duyguların aynı anda hissedilebildiği duygusal çatışmalı bir süreçtir (Yas İyileştirme Ensitüsü (Grief Recovery Institute [GRI], 2009). Yas süreci sadece hasta, vefat ettikten sonra değil, vefat öncesinde de yakınları tarafından yaşanabilen bir duygudur (Nanni, Biancosino ve Grassi, 2014; Tomarken, 2008). Terminal dönemdeki bir hastanın vefatıyla hastalıktan ve acılı süreçten kurtulduğu için sevinirken bundan sonra onsuz yaşayacağı için üzüntü yaşıyor olmak gibi iki zıt duygunun bir arada yaşanıyor olmas1, yas sürecinde sık karşılaşılabilen bir durumdur. Diğer yandan; yas sürecinin yaşanması sadece sevilen kaybıyla değil sevgi dolu olunmayan birinin kaybıyla da ortaya çıkabiliyor. Sevilen birinin vefatıyla yaşanan yas süreci "Her ihtiyaç duyduğunda orada olan birinin, bir kez daha ihtiyaç duyduğunuzda artık orada olmaması" olarak tanımlanıyor. Sevgi dolu olunmayan kişinin vefatındaki yas ise "İhtiyaç duyduğunuzda hiçbir zaman orada olmayan birinin bir kez daha ihtiyaç duyduğunuzda yine orada olmaması" şeklinde tanımlanıyor (GRI, 2009).

\section{Yas Sürecindeki Tepkiler}

Kayıp sonrasında kişilerin yas sürecindeki tepkileri değişkenlik gösterebiliyor. Evrensel olarak herkesin aynı tepkileri göstermediği gibi, bir kişi her kayıpta yas sürecini farklı tepkilerle yaşayabilir. Bu tepkiler hem vefat eden kişiyle ilişkiye göre değişkenlik gösterirken yas sürecindeki kişinin yasını ifade ediş şekline göre de değişebiliyor. Kişilik özellikleri, vefat sebebi, vefata hazırlık süreci, vefat haberinin öğreniliş şekli veya kültürel ve dini inançlar yas sürecindeki farklı tepkilere etken olabiliyor.

Elizabeth Kubler Ross (2005), yastan iyileşmek için kişilerin şok, inkâr, öke, pazarlık ve kabullenme aşamalarını tamamlanması gerektiğini açıklıyor. 2000li yıllarda ise hiçbir yas aşama teorisinin herkesin yas sürecindeki tepkilerini kapsayacak kadar geçerli olabilen bir yas aşama teorisinin olamayacağ 1 görüşü savunulmaya başlandı (Weiskittle ve Gramling, 2018; Zisook ve Shear, 2009). Benzer şekilde yas yaşama ve tamamlanma süresinin de sinırlandırılamayacak kadar çeşitli olduğu, 18 ay kadar bile sürebileceği savunuluyor (Zisook \& Shear, 2009).

\section{Normal Yas ve Çözümlenmeyen Yas Süreç Karşılaştırılması}

Hasta yakınının yaşadığı yas süreci semptomlarının normal ve çözümlenmemiş yas ile ayrıştırılması, kişinin ihtiyacı olduğu psikolojik desteği sağlayabilmek açısından önemlidir. Çözümlenmeyen yas, normal yas sürecini yaşamamak veya normal yas sürecinin geçmiş olmasına rağmen, kişinin duygudurumunda değişim yaşanmamasıdır. Çözümlenmemiş yas yaşayan kişi; 12 ay geçmiş olmasına rağmen öldüğünü kabul etmek istemeyebilir, dinmeyen duygusal hissizlik, yalnızlık, hayat amaçsızlığı, izolasyon isteği, öfke, suçlama veya ac1 yaşayabilir, onunla ölmüş olmak üzerine dürtü ve planlar akıldan geçebilir, zihnin sürekli ölen kişiyle meşgul olabilir veya ölen kişiyi ilahlaştırma gibi normal dışı algılar yaşayabilir (Amerikan Psikiyatri Birliği, 2014; American Cancer Society, 2019; Jordan ve Litx, 2014; Prigerson ve ark., 2009). Tetikleyici olarak; vefat edenin birinci dereceden yakını olmak, çocukluğunda ayrılma anksiyetesi yaşamış olmak, önceden ebeveyn kaybı ya da taciz yaşamış olmak, kontrolcü ebeveynlerle yetişmiş olmak, öncesinde zayıf fonksiyonlu evlilik veya beklenmeyen ölüm olduğu görülüyor (Ott, Lueger, Kelber ve Prigerson, 2007).

Yakının vefatı sonrasında normal yas, ısrarcı ve yoğun yaşanmazken, çözümlenmeyen yas günlük yaşamı ilişkileri tehdit edecek düzeyde olabilir. Çözümlenmeyen yas yaşıyor olmak kişinin; normal yas sürecini yaşamasına engel olabilir, ölümle ilgili ruminasyon yaşayıp, hayatta kalmış olmakla ilgili tıkanmışlık hissi yaşamasına sebep olabilir. Bu komplike duygudurum hali, giderek stres ve fonksiyonel bozulmaya sebebiyet verebilir. Çözümlenmeyen yas yaşayan kişi; kendisine ve yaşama dair değer ve ilgi kaybı, başkalarından kopukluk hissi ve yastan çıkmanın ihanet olacağına inanırken; normal yas yaşayan kişi, kriz günlerinin ardından yaşadığı acıya rağmen günlük yaşam ve sorumluluklarına dönebilir, yaşama ilgisi yeniden anlamlanır ve yas duygularını istediği şekilde ifade edebilir (Prigerson ve ark., 1997).

Kansere bağlı vefatın ardından yakını olarak, sadece o kişinin kaybını değil; sevdiğinin sağlığı, iş birliğini de kaybediyor; hastalık öncesi yaşanan anılar, hayaller, geleceğe yönelik yapılacak planlar, ekonomik güvenceyi de kaybetmiş oluyor. Hastalığın ve sürecin getirdiği 
birçok değişkenle beraber ilişki de kaybolur. $\mathrm{Bu}$ denli yoğun duygusal anlam ve kayıplarla bağlantılı olarak kanser hasta yakınlarında, çözümlenmeyen yas yaşama oranının kanser dışındaki kayıp yaşayanlardan daha fazla olduğu görülüyor (\%10-20) (Cruse, 2017).

Kansere bağlı vefat sonrasında hasta yakının yas sürecini kolaylaştıran bazı faktörler vardır. Bakım süresinin uzun olması, bakım verenin tıbbi hastalık öykü varlı̆̆1, tedavinin olanaksız olduğu bir bölümde bakımının sağlanıyor olması da yas ve kabullenme sürecini kolaylaştırabilir (Chiu ve ark., 2010; Schulz, Hebert ve Boerner, 2008). Kolaylaştırıcı faktörlere rağmen iyileştirilmediğinde, kısa sürede majör depresyon ve travma sonrası stres bozukluğu (Latham ve Prigerson, 2004); uzun sürede de fonksiyonel bozulma, hipertansiyon, kalp hastalıkları gibi fiziksel sağlık problem gelişim riski artıyor (Boelen, 2013). Kadınlarda, kaybedilenin ebeveyn-çocuk/eş gibi hayat paylaşılan kişi olduğunda, inançlı olmamak, yetersiz aile desteği, güvensiz bağlanma ilişki yapısı ve duygudurum öykü varlığı olan kişilerde risk artıyor (Carlo ve ark., 2015; Chiu ve ark., 2010; Doorn, Kasl ve Beery, 1998).

\section{Yas Sürecinde Etkili Yaklaşımlar}

Kansere bağlı vefat sonrasında hasta yakınında, yas sürecini yaşayışına bağlı olarak psikososyal ihtiyaçlar oluşabilir. Psikososyal ihtiyaçların karşılanması için kurumların sunduğu veya kişilerin başvurabileceği birçok yaklaşım vardır.

Ulusal Kanser Enstitüsü (2014), kanser sürecindeki bakım, ölüm süreci ve sonrası için ailelere duygusal desteği ölüm sonrasında da uygulayan ilk kurumdur. Bu birimde, nöroonkoloji ekip üyelerinin imzalarının olduğu sempatik taziye mektup kartı gönderiliyor; kayıp sonrası 1 y1l telefon aramaları yapılıyor; ihtiyaç görüldüğünde yas iyileştirme hizmetine yönlendirebiliyor (Lima, Cavaliere ve Porensky, 2014). Kanser farkındalığını arttırmak için her bir kanser türü yılın bir ayında dünyaca temsil ediliyor, duyuruları yapılıyor ve o kansere yönelik ücretsiz hizmetler sunulabiliyor. Ulusan Kanser Enstitüsü destek biriminde "Anma Hizmeti" adiyla o aylarda buluşma günü belirleniyor ve hem ailelerin hem hekimlerin katılarak vefat eden hastalar anılıyor. Böylece yas sürecinin tamamlanması desteklenmiş (Lima ve ark., 2014).

Ruh sağlığı uzmanları tarafından sağlanan psikolojik yaklaşımlara bakıldığında etkinliği kanıtlanan konuşma terapileri olarak çözümlenmemiş yas terapisi, ifade edicidestekleyici danışmanlık, yas iyileştirme programı ve kognitif (bilişsel) davranışçı terapi olduğu görülüyor.

Çözümlenmemiş yas terapisinin birçok farklı uygulama yöntemi vardır. Shear, Frank, Houck ve Reynolds (2005) özellikle depresif semptomlar yaşayanlar için 16 seanstan oluşan üç aşamalı program geliştirmiştir. Bu programda önce yasla ilgili psikoeğitim, kayıp sürecinin önemi, yaşamsal fonksiyonların yeniden oluşturulması ve kayıp sonrasında durdurduğu hedeflerine odaklanılır. $\mathrm{Bu}$ ön hazırlık aşamasının ardından pozitif ve negatif tüm hatırlanan anıları yazma egzersizi, göz kapalı ziyaret gibi görsel ve konversiyonel imajinasyonla maruz birakma yöntemleriyle kayba odaklanılan uygulamalar yapılır, ses kaydedilip evde dinlemesi istenir. $\mathrm{Bu}$ aşamanın tamamlanmasıyla çözümlenmemiş yas semptomlarından ayrışan kişiyle artık üçüncü aşama olan restorasyona odaklanma egzersizleri çalışılmaya başlanır. Yaratıcılık, yaşam amaçlarının gerçekleşmesine yönelik somut planlar ve keyifli aktiviteler yeniden yaşama entegre edilir. Vefat eden kişiyi hatırlattığı için yok sayılan, gidilmeyen, yapılmayanlara yaklaşması için cesaretlendirilir

İfade edici-destekleyici danışmanlık yaklaşımında kayba yönelik hissedilen üzüntü, kızgınlık, öfke gibi duygu ve düşüncelerin sözel aktarımı sağlanır. Fiziksel ve ruhsal iyilik halini güçlendirmek için diğer aile üyelerine, sağlık ekibine, dini inancına, arkadaş, akraba veya sosyal gruplar gibi ilişsilerin iyileştirilmesi, geliştirilmesi ya da yenilenmesine yönelik çalışmalarda bulunulur (Boelen, de Keijser, van den Hout ve van den Bout, 2007).

Yas iyileştirme programı, Yas İyileştirme Enstitüsü (GRI, 2009) tarafından geliştirilen 6-8 oturumda tamamlanan yapılandırılmış kanıta dayalı bir programdır (Nolan ve Hallam, 2019a; Nolan ve Hallam, 2019). Programın ana amac1, kayıba yönelik yaşanan çözümlenmeyen yas ve yarım kalan duygularının aktarılarak tamamlanabilmesini sağlamaktır. Böylelikle kişi, olumlu ve olumsuz yaşadığ tüm anı ve duygularını aktarıp yarım kalanların artık gerçekleşmeyeceği gerçeğini kabul eder, yasını tamamlar ve normal yaşamına döner. Çözümlenmeyen yas yaşamanın ana sebebi aktarılamayan duygulardır (GRI, 2009). Bu programda kayıp yaşanan kişiye yönelik de çalışılabiliyor, yaşanan hastalığa, hayal kırıklığı yaşatan doktor, anne, baba, tedavi, Allah ya da diğer yas yaşamaya yol açan şeye yönelik çalışılabiliyor.

Kognitif davranış̧̧ı terapi, Aaron Beck tarafından 1960'lı yıllarda öncelikle depresyon tedavisi için geliştirilmiştir (Türkçapar, 2007). Kognitif davranışçı terapi, yas sürecinin yaşandığı birçok durumda etkili olduğu gibi kanser hasta yakını olarak yaşanan kayıp sonrasında duyguların iyileşmesinde de etkilidir (Boelen ve ark., 2007; National Cancer Institute, 2017). Kognitif terapinin en temelinde, kişinin düşünce, duygu, fiziksel belirti ve davranışları arasındaki bağlantı üzerinde çalışılır (Beck, 2001). Zorlayıcı negatif düşünce, davranış ve tutum değişimi için öğrenilen etkili becerilerin günlük yaşam akışında yapılan pratiklerle içselleştirmesi sağlanır. Böylelikle terapi görüşmeleri haftada bir gelip gidilen 1 saatlik rahatlama değil, bisiklet kullanmayı öğrenmiş olup yıllar geçtiğinde dahi unutmuyor olma becerisi kazanmış olmak gibi ruhsal iyileşme tekniklerini öğrenip bundan sonraki yaşamı boyunca kendi terapisti olabilmesi sağlanır.

Kayıp sonrası yaşanan yas; depresyon veya diğer psikiyatrik bozukluklarla birleştiğinde/dönüştüğünde psikofarmakolojik tedaviye yönlendirilir. Özellikle kendine ya da başkasına zarar verici düşünce, dürtü, plan, ya da girişimler söz konusuysa, uyku problemleri, depresif duygudurum, anksiyete, öfke veya kaygıya yönelik zorlanmalar günlük yaşamını, iş, aile, veya sosyal çevre ilişkilerini de kapsamaya başladığında psikiyatrik destek ve konsültasyon en öncelikli şart olur. Ancak kaybedilen kişiye yönelik çözümlenmeyen yas yine çalışılması gereken çözümlenmeyen bir boğum olarak kişiyle yaşamaya devam eder (Jordan ve Litx, 2014).

\section{Onkologların Tükenmişlikle Baş Etme Yolları}

Tüm mesleklerde yaşanabileceği gibi onkologlar da iş ve yüküne bağlı gelişen stres yaşayabilirler. İşe ya da iş yüküne bağlı gelişebilen bu stresör önce mutsuzluk, 
yorgunluk, isteksizlik ya da keyif alamama gibi depresif duygudurum, kaygı, ya da yorgunluk gibi kişisel strese yol açıp ardından tükenmiş hissetmeye yol açabilir. $\mathrm{Bu}$ tükenmişlik hissi, günlük yaşamını aile, iş, sosyal yaşamıyla hasta ve yakınlarına yönelik tahammül ve verimliliğini olumsuz yönde etkileyebilir (Maslach, Schaufeli ve Leiter, 2001). Tükenmişliğin 3 anahtar uzantısı vardır; 1. aşırı yorgunluk 2. depersonalizasyon (kendine yabancılaşma- sinicilik, şüphecilik, işe yönelik objektifliği kaybetme hissi) ve 3. etkisiz, işe yaramaz ve başaramayacak olma hisleridir (Langenaeken ve Rombouts, 2014). Yorgunluk, tükenmişliğin en tabanındaki yetersizlik düşüncesiyle ortaya çıkan temel unsurdur. Kronikleşen yorgunluk, duygusal ve kognitif olarak kişinin işine yönelik motivasyon ve özyeterlilik inancından uzaklaşmasına sebep olabilir. 3 hafta-3 ay arası bitmeyen yorgunluk, kendi kimliğinden, yaşam amacından uzaklaşma, amaçsızlaşma, uygulanan tedavilerin işe yaramazlığ yaramazlığ 1 gibi hisler yoğun ve 1 srarc1 ise bu hekimin gerçekte yetersiz, başarısız, hayatın amaçsız, anlamsız olmasından değil; artık "tükenmiş" olmasından kaynaklanıyor olabilir. Tipkı bir pilin bataryasının kalmamış olması ya da bir cep telefonunun şarjının bitmiş olması gibidir ve şarj edildiğinde işlevini kaldığı yerden devam ettirebilir. İçinde bulunulan iş yoğunluğu çoğu zaman yaşanılan yorgunluğun tükenmişlik sendromundan kaynaklandığını fark ettirmeyebilir. $\mathrm{Bu}$ sebeple 3 haftadan uzun süredir hissedilen tükenmişliğe yönelik semptomlar yaşandığında ülkemizde geçerlilik güvenilirliği yapılmış olan ölçeklerden yararlanılabilir. "Maslach Tükenmişlik Ölçeği (Maslach Burnout Inventory (MBI)" ruhun ihtiyacinı belirleyebilmek için kolaylıkla ve sıklıkla onkologların başvurabileceği Türkçe geçerlilik güvenilirlik çalışmasının yapıldığ 1 ölçeklerdendir (Ergin, 1992). Maslach tükenmişlik ölçeği ile onkoloji ekibindeki tükenmişlik çalışmalarına bakıldığında medikal onkologların \%25-35, radyasyon onkologlarının \%38, cerrahi onkologların \%28-36 oranında tükenmişlik yaşadıkları görülmektedir (Shanafelt ve Dyrbye, 2012). Bu çalışma aslında kanser hasta yakınlarındaki yas kadar, alanda çalışan onkologlarımızın da psikolojik ihtiyaçlarının olabileceğini, onlarında insan olduğunu ve insani ihtiyaçlarının olabileceğini hatırlamamızı sağlıyor.

\section{Onkologların Kendine Bakımı/Öz-Bakım}

Onkoloji alanında çalışmak kendi içinde kişisel ödüllendiriciliğe sahip olsa da, zahmetli, emek gerektiren ve stres dolu bir meslektir. İşle bağlantılı problemlerde, iş, yaşam dengesinin bozulması her insanda olabileceği gibi onkologlarda da en temelinde insan oldukları için stres hormonlarını tetikleyebilir ve tükenmişlik/yakıt bitimi yaşatabilir. Kişisel iyilik halini yükseltmeye, yaşam kalitesini artırmaya yönelik, iş, sosyal, aile ve günlük yaşam akışı içerisinde minik değişimler verim, tatmin ve dayanıklılığı artırabilir. Rehberli intervizyon gibi süpervizyon, ekip toplantısı ya da vaka tartışması dışında tedavi ve bakımın tartışıldığı formatların özellikle işle bağlantılı tükenmişlik yaşayan kişilerde etkili olduğu görülüyor (Langenaeken ve Rombouts, 2014). İntervizyon; profesyonellerinin iş kalitesini iyileştirme amacıyla yapılandırılmış grup konsültasyonudur. Buluşma gerçekleştirdiğinde saygı, güven ve herkesin eşit haklara sahip olması gibi ana kurallara uyularak, yuvarlak düzendeki sandalyeden farklı olarak merkezde bir kişi oturur ve profesyonel yaşamındaki tıbbi ya da duygusal tıkanıklığını samimiyetle paylaşarak gruptaki diğer kişilerin fikir, ipucu, öneri, bilgi ya da tecrübelerin duyulması sağlanır (Langenaeken ve Rombouts, 2014). Kendilerini rahatça ve güvenle ifade edebilen profesyoneller, bu buluşmalara katılarak bilgi, tecrübe ve öz-ifade becerilerinin artışı ve işle ilişkili duygularla nasıl baş edilebileceğine yönelik iyileşme ve iyi hissetmek hedeflenir. En önemlisi yalnız olmadığı, benzer tıkanıklıkların ve duyguların diğer hekimler tarafından da yaşanabiliyor olduğu fark edilir (Trautmann, 2010).

\section{Sonuç}

Kanser hastalı̆̆ı, hastanın kendisi kadar yakınlarının da yas yaşamasına yol açabiliyor. Normal yas süreci tamamlanamadığında yaşanan çözümlenmemiş yas için, psikolojik etkili yaklaşımlardan yararlanılması önemlidir. Kanser hasta yakınlarının yas sürecini sağlıkla tamamlayabilmelerine yönelik yapılan çalışmalar; çözümlenmemiş yas terapisi, ifade edici-destekleyici danışmanlık, yas iyileştirme programı ve kognitif (bilişsel) davranışçı terapinin etkili olduğunu gösteriyor. Diğer önemli husus tedavi ekibinin olası tükenmişlik sendrom yaşama durumunda farkında olması ve etkili yöntemlerle baş edebilmesidir. Literatür tarandığında, onkologların tükenmişlik sendromu yaşamaları durumunda etkili olarak baş edebileceği yöntem olarak; iş ve günlük yaşamın diğer alanındaki stres yönetim becerilerini geliştirmek, stresörlere çözüm odaklı yaklaşmak, yaşam kalitesini arttırmak üzerine davranışsal değişimler uygulanabilir. Ayrıca, diğer tedavi ekip üyeleri veya meslektaşlarıyla birlikte grup intervizyonu oluşturularak; yaşadığı tükenmişliği başkalarının da yaşadığını, nasıl baş ettiğini öğrenmek ve kendi duygularını aktararak, psikolojik iyi hissetme düzeyi arttırılabilir.

\section{Kaynaklar}

Altilio, T., Gardia, G., \& Otis-Green, S. (2008). Social Work Practice In Palliative and End-of-Life Care: A Report From The Summit. Journal Of Social Work in End Of Life \& Palliative Care, 3(4), 68-86. Doi:10.1080/15524250802003513

American Cancer Society. Symptoms of Major Depression and Complicated Grief. Atlanta: American Cancer Society; 2019.

American Psychiatric Association (2013). Diagnostic and Statistical Manual of Mental Disorders (5th ed.). Arlington, VA: American Psychiatric Publishing.
Amerikan Psikiyatri Birliği (2014). Ruhsal Bozuklukların Tanısal ve Sayımsal El Kitabı Beşinci Baskı (DSM-5). Köroğlu, E. (Çeviri editörü), Ankara: Hekimler Yayın Birliği, 1094-1098

Beck, J. (2001). Bilişsel Terapi Temel İlkeler ve Ötesi. Çev: Şahin, N. H. Türk Psikologlar Derneği Yayınları

Boelen, P. A. (2013). Symptoms of prolonged grief, depression, and adult separation anxiety: Distinctiveness and correlates. Psychiatry research, 207(1-2), 68-72. https://doiorg.ezp.waldenulibrary.org/10.1016/j.psychres.2012.09.021 
Boelen, P. A., de Keijser, J., Van Den Hout, M. A., \& Van Den Bout, J. (2007). Treatment of complicated grief: A comparison between cognitive-behavioral therapy and supportive counseling. Journal of Consulting and Clinical Psychology, 75(2), 277-284. https://doi.org/10.1037/0022-006X.75.2.277

Boelen, P. A. \& Prigerson, H.G. (2007). The influence of symptoms of prolonged grief disorder, depression, and anxiety on quality of life among bereaved adults: a prospective study. European archives of psychiatry and clinical neuroscience, 257, 444-452

Carlo, L., Massimiliano, L., Federico, G., Emanuela, M., Roberta, C., Italo, P., \& Luigi, L. (2015). Attachment style dimensions can affect prolonged grief risk in caregivers of terminally ill patients with cancer. American Journal of Hospice \& Palliative Medicine,8, 855. doi:10.1177/1049909114547945

Chiu, Y.W., Huang, C.T., \& Yin, S.M. (2010). Determinants of complicated grief in caregivers who cared for terminal cancer patients. 18, 1321. https://doi.org/10.1007/s00520-009-0756-6

Correspondence and Comments-Cautioning Health-Care Professionals: Bereaved Persons Are Misguided Through the Stages of Grief (Omega-Journal of Death and Dying, 74.4). (2017). Omega, 75(1), 92-94. https://doiorg.ezp.waldenulibrary.org/10.1177/0030222817701499

Cruse (2017). Current Issues in Grief Therapy: Complicated Grief. $\quad$ Retrieved from http://www.cruse.org.uk/sites/default/files/default_images/pdf/E vents/ColinMPcomplicatedgrief.pdf van Doorn, C., Kasl, S. V., Beery, L. C., et al. (1998). The influence of marital quality and attachment styles on traumatic grief and depressive symptoms. $\mathbf{J}$ Nerv Ment Dis 186 (9): 566-73, 1998

Ergin, C. (1992). Doktor ve hemşirelerde tükenmişlik ve Maslach Tükenmişlik Ölçeğinin uyarlanması, VII. Ulusal Psikoloji Kongresi, Hacettepe Üniversitesi, Ankara.

Glajchen, M. (2004). The emerging role and needs of family caregivers in cancer care. Journal of supportive oncology, 2, $145-155$.

Grimby, A. (1993). Bereavement among elderly people: grief reactions, post-bereavement hallucinations and quality of life. Acta Psychiatrica Scandinavica, 87: 72-80. doi:10.1111/j.16000447.1993.tb03332.x

Gorman, L. M. (n.d.). The Psychosocial Impact of Cancer on the Individual, Family, and Society. Retrieved from https://www.ons.org/sites/default/files/publication_pdfs/Sample \%20Chapter\%200554\%20PsyNsgCare2nd.pdf

Jordan, A. H., \& Litx, B. T. (2014). Prolonged Grief Disorder: Diagnostic, Assessment, and Treatment Considerations. Professional Psychology, Research and Practice, 45(3), 180187.

Kubler-Ross, E. \& Kessler, D. (2009). On grief and grieving: finding the meaning of grief through the five stages of loss [Ölüm ve ölmek üzerine]. NewYork, NY: Simon and Schuster.

Langenaeken, C., \& Rombouts, W. (2014). Caring for the oncologist: caregiver stress and staff support in oncology. Belgian Journal of medical oncology, 8(2), 38-43.

Latham, A., E. \& Prigerson, H.,G. (2004). Suicidality and bereavement: complicated grief as psychiatric disorder presenting greatest risk for suicidality. Suicide Life Threating Behavior, 34(4), 350-362

Lederberg, M. S. (1998). The family of the cancer patient. In J.C. Holland (Ed.), Psycho-oncology (pp. 982-993). New York: Oxford University Press

Lima, J., Cavaliere, R., \& Porensky, E. (2014). Closing the Gap: Bereavement Support for Families, Caregivers, and Medical Staff. Neuro-oncology, 16.https://doi-

org.ezp.waldenulibrary.org/10.1093/neuonc/nou269.17
Maslach, C., Jackson S., \& Leiter, M. (1996). Maslach Burnout Inventory Manual. 3rd ed. Palo Alto, CA: Consulting Psychologists Press.

Maslach, C., Schaufeli, W. B., \& Leiter, M. P. (2001). Job burnout. Annual Review of Psychology, 52, 397-422.

Nanni, M. G., Biancosino, B., \& Grassi, L. (2014). Pre-loss symptoms related to risk of complicated grief in caregivers of terminally ill cancer patients. Journal of affective disorders, 160 , 87-91. doi:10.1016/j.jad.2013.12.023

National Cancer Institute (2017). Grief, bereavement, and coping with loss (PDQ $®)$-health professional version. Retrived from https://www.cancer.gov/about-cancer/advancedcancer/caregivers/planning/bereavement-hp-pdq

National Institutes of Health (2014). Caring for caregiver. 14$6219 . \quad$ Retrieved from https://www.cancer.gov/publications/patient-education/caringfor-the-caregiver.pdf

Nolan, R. D. \& Hallam, J. S. (2019a). Construct validity of the theory of grief recovery (TOGR): A new paradigm toward our understanding of grief and loss. American Journal of Health Education 50:2, pages 88-98.

Nolan, R. D. \& Hallam, J. S. (2019b). Measurement development and validation for construct validity of the treatment: The grief recovery method instrument (GRMI). American Journal of Health Education 50:2, 99-111.

Northouse, L. L. (2005). Helping families of patients with cancer. Oncology Nursing Forum, 32, 743-750.

Ott, C. H. (2003). The impact of complicated grief on mental and physical health at various points in the bereavement process. Death Studies, 27(3), 249-272. Retrieved from https://ezp.waldenulibrary.org/login?url=https://search.ebscohost .com/login.aspx ?direct $=$ true $\& \mathrm{db}=\mathrm{mnh} \& \mathrm{AN}=12703505 \&$ site $=\mathrm{ed}$ s-live \&scope $=$ site

Özer, Ü., \& Yıldırım, E., A. (2015). Komplike yas ve komplike yas tedavisi. The Journal of Psychiatry and Neurological Sciences, 28, 281-282.

Prigerson, H. G., Bierhals, A. J., Kasl, S. V., Reynolds, C. F., 3rd, Shear, M. K., Day, N., ... Jacobs, S. (1997). Traumatic grief as a risk factor for mental and physical morbidity. The American Journal Of Psychiatry, 154(5), 616-623. Retrieved from https://ezp.waldenulibrary.org/login?url=https://search.ebscohost $. c o m / \operatorname{login}$. asp $x$ ?direct $=$ true $\& d b=m n h \& A N=9137115 \&$ site $=$ edslive \&scope $=$ site

Prigerson, H., G., Horowitz, J., M., Jacobs, S.,C., Parkes, C., M., Aslan, M., Goodkin, K. ... Maciejewski, P.K. (2009). Prolonged grief disorder: Psychometric validation of criteria proposed for DSM-V and ICD-11. PLoS Medicine, 6(8). https://doiorg.ezp.waldenulibrary.org/10.1371/journal.pmed.1000121

Schroepfer, T. A., \& Noh, H. (2010). Terminally ill elders' anticipation of support in dying and in death. Journal of social work in end-of-life \& palliative care, 6(1-2), 73-90. https://doiorg.ezp.waldenulibrary.org/10.1080/15524256.2010.489223

Schulz, R., Hebert, R., \& Boerner, K. (2008). Bereavement after caregiving. Geriatrics, 63(1), 20-22.

Shanafelt, T. \& Dyrbye, L. (2012). Oncologist burnout: causes, consequences, and responses. Journal of Clinical Oncology, 30, $1235-41$.

Shear, K., Frank, E., Houck, P. R., \& Reynolds, C. F., 3rd (2005). Treatment of complicated grief: a randomized controlled trial. JAMA, 293(21), 2601-2608. doi:10.1001/jama.293.21.2601

Shell, J.A., \& Kirsch, S. (2001). Psychosocial issues, outcomes, and quality of life. In S.E. Otto (Ed.), Oncology nursing (4th ed., pp. 948-972). St. Louis, MO: Mosby 
Stajduhar, K. I., Martin, W., \& Cairns, M. (2010). What makes grief difficult? perspectives from bereaved family caregivers and healthcare providers of advanced cancer patients. Palliative \& SupportiveCare, 8(3),277-89.

doi:http://dx.doi.org.ezp.waldenulibrary.org/10.1017/S14789515 1000007

Stuart, M. R., \& Lieberman, J. A. (2002). The fifteen minute hour: practical therapeutic interventions in primary care. 3rd ed. Philadelphia: Saunders.

Tomarken, A., Holland, J., Schachter, S., Vanderwerker, L., Zuckerman, E., Nelson, C., Prigerson, H. (2008). Factors of complicated grief pre-death in caregivers of cancer patients. Psycho-Oncology, 17(2), 105-111. Retrieved from https://ezp.waldenulibrary.org/login?url=https://search.ebscohost .com/login.aspx ?direct $=$ true $\& d b=m n h \& A N=17443644 \&$ site $=e d$ s-live\&scope =site
Trautmann, F. (2010). Intervision guidelines. Retrieved from https://www.unodc.org/documents/balticstates/Library/Pharmaco logicalTreatment/IntervisionGuidelines/IntervisionGuidelines.pd

Türkçapar, H. (2007). Bilişsel Terapi Temel İlkeler ve Uygulama. HYB Yayıncılık.

Weiskittle, R. E., \& Gramling, S. E. (2018). The therapeutic effectiveness of using visual art modalities with the bereaved: a systematic review. Psychology research and behavior management, 11, 9-24. doi:10.2147/PRBM.S131993

Zisook, S., \& Shear, K. (2009). Grief and bereavement: what psychiatrists need to know. World Psychiatry 8: 67-74.

Zisook, S., \& Shuchter, S. R. (1993). Uncomplicated bereavement. J Clin Psychiatry. 1993;54(Suppl):365-372.

Zisook, S., \& Shuchter, S. R. (1996). Psychotherapy of the depression in spousal bereavement. Psychotherapy in Practice, 2, $31-45$. 